\title{
Overview of Industrial Materials Detection Based on Prompt Gamma Neutron Activation Analysis Technology
}

\author{
Jiawen Fan, Jie Xu, Changming Wang \\ Chengdu University of Technology, Chengdu, China \\ Email: 1533386277@qq.com
}

How to cite this paper: Fan, J.W., Xu, J. and Wang, C.M. (2020) Overview of Industrial Materials Detection Based on Prompt Gamma Neutron Activation Analysis Technology. World Journal of Engineering and Technology, 8, 389-404. https://doi.org/10.4236/wjet.2020.83030

Received: June 28, 2020

Accepted: July 27, 2020

Published: July 30, 2020

Copyright (c) 2020 by author(s) and Scientific Research Publishing Inc. This work is licensed under the Creative Commons Attribution International License (CC BY 4.0).

http://creativecommons.org/licenses/by/4.0/

\begin{abstract}
Prompt gamma neutron activation analysis (PGNAA) is a non-destructive online measurement nuclear analysis method. With its unique advantages, it has been widely used in online analysis of industrial materials such as coal, cement, and minerals in recent years. However, there are many kinds of literature on PGNAA in the field of industrial materials detection, and there are still a few concluding articles. To this end, based on the principle of PGNAA online analysis, the status quo and development of the real-time online detection of industrial material components in the field are reviewed and discussed by consulting a large number of domestic and foreign PGNAA related literature and data, to facilitate the reference of relevant scientific researchers.
\end{abstract}

\section{Keywords}

Prompt Gamma Neutron Activation Analysis Method, PGNAA, On-Line Detection of Industrial Materials

\section{Introduction}

Industrial material composition real-time online detection technology is a real-time and accurate online analysis and detection technology for material composition in the process of industrial feeding and batching. It can be widely used in industrial production processes such as coal, cement and minerals. It is an important means to promote the upgrading and transformation of traditional heavy industry enterprises and to energy-saving and emission reduction.

At present, the main means of real-time online detection of industrial material components are: X-ray fluorescence analysis technology, infrared analysis, neutron activation analysis (NAA) and prompt gamma neutron activation analysis 
technology (PGNAA). Among them, due to the limitations of the characteristics of the radiation source used, X-ray fluorescence and infrared analysis techniques can only analyze the composition of the surface layer for bulk materials, but cannot perform volume analysis. NAA technology can be used for non-destructive measurement with high sensitivity and good accuracy, but it cannot be used for real-time online analysis. Moreover, it is more powerless for the determination of some light elements (such as H, B, N, P, etc.) [1]. The PGNAA technology has a significant advantage in the sensitivity of non-destructive light element analysis. At the same time, because both neutrons and $\gamma$-rays have strong penetrating capabilities, the entire element information of bulk materials can be obtained, so this technology has become the best choice for industrial bulk material composition testing needs [2] [3] [4]. Table 1 compares the four online analysis technologies.

Prompt Gamma Neutron Activation Analysis (PGNAA) is a non-destructive, efficient, multi-element online nuclear analysis technology [5]. In principle, it can measure most of the elements on the periodic table [6], especially in the analysis of elements with large (n, $\gamma$ ) reaction cross-sections (B, Cd, Gd, H, etc.), its sensitivity is high, and it is usually used as a supplement to conventional analysis, the analysis of light elements in large samples is the only method [7].

Based on relevant international studies, this paper discusses PGNAA technology from the following four aspects: The first part briefly summarizes the basic principle of PGNAA technology and its development direction in recent years; The second part introduces the theoretical research of PGNAA technology in industrial material detection. Further, in the third part of the paper, it mainly discusses the international research on the application of PGNAA technology in industrial material detection system equipment. Finally, in the conclusion part, it summarizes the industrial application of PGNAA technology.

\section{The Principle and Development Direction of PGNAA Technology}

\subsection{Basic Principles}

The technical principle of Prompt gamma neutron activation analysis (PGNAA) is shown in Figure 1. When the neutron beam emitted by the neutron source bombards the nucleus of the measured substance, undergoes a nuclear reaction (mainly inelastic scattering nuclear radiation capture) and emits instantaneous characteristic gamma rays in a very short time. These characteristics $\gamma$ are collected through the detection system, and qualitatively and quantitatively analyzing the elemental composition and content of the measured material by analyzing the energy and intensity of these characteristic $\gamma$ rays [8].

In PGNAA technology, the intensity of $\gamma$ rays with a certain energy can be given by the following formula [9]:

$$
A(t)=\phi \frac{\omega}{M} N_{A} \alpha \sigma \lambda \varepsilon
$$




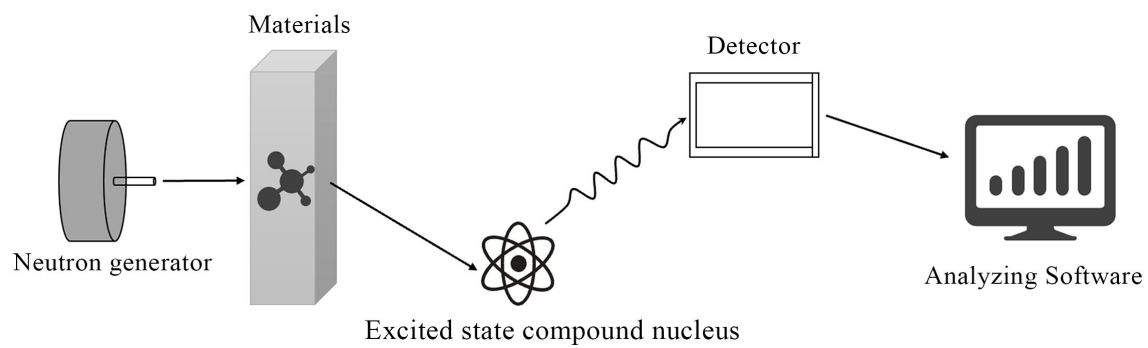

Figure 1. The principle of the Prompt gamma neutron activation analysis technique.

Table 1. Comparison of four online analysis technologies.

\begin{tabular}{|c|c|c|c|c|}
\hline Project & $\begin{array}{l}\text { Infrared } \\
\text { technology }\end{array}$ & $\begin{array}{l}\text { X-ray } \\
\text { fluorescence } \\
\text { analysis }\end{array}$ & $\begin{array}{l}\text { Neutron } \\
\text { Activation } \\
\text { Analysis }\end{array}$ & $\begin{array}{l}\text { Prompt Gamma } \\
\text { Neutron Activation } \\
\text { Analysis }\end{array}$ \\
\hline $\begin{array}{l}\text { Simultaneous } \\
\text { measurement of } \\
\text { multiple elements }\end{array}$ & Yes & $\begin{array}{l}\text { Atomic } \\
\text { number }>12\end{array}$ & $\begin{array}{l}\text { Yes (Except H, C, O, } \\
\text { etc.) }\end{array}$ & Yes \\
\hline $\begin{array}{l}\text { Granularity } \\
\text { requirements }\end{array}$ & $\begin{array}{l}\text { Have higher } \\
\text { requirements }\end{array}$ & $>6 \mathrm{~mm}$ & None & None \\
\hline $\begin{array}{l}\text { Influence of } \\
\text { surrounding } \\
\text { environment }\end{array}$ & $\begin{array}{l}\text { Affected by dust, } \\
\text { humidity, etc. }\end{array}$ & None & None & None \\
\hline $\begin{array}{l}\text { Real-time online } \\
\text { analysis }\end{array}$ & Yes & Yes & $\begin{array}{l}\text { Offline } \\
\text { measurement }\end{array}$ & Yes \\
\hline $\begin{array}{l}\text { Measurement } \\
\text { method }\end{array}$ & Surface & Near surface & $\begin{array}{l}\text { Volume } \\
\text { measurement }\end{array}$ & $\begin{array}{l}\text { Volume } \\
\text { measurement }\end{array}$ \\
\hline Accuracy & Poor & Poor & Very high & Good \\
\hline Regular correction & Yes & Yes & No & No \\
\hline $\begin{array}{l}\text { Radioactivity } \\
\text { around the } \\
\text { instrument }\end{array}$ & None & $\begin{array}{l}\text { Within safe } \\
\text { range }\end{array}$ & Within safe range & Within safe range \\
\hline
\end{tabular}

$A(t)$ is the count of a certain energy $\gamma$-ray in time $t ; \phi$ represents the neutron flux; $\omega$ represents the mass of the detected element; $M$ represents the atomic weight of the detected element; $N_{A}$ represents the Avogadro constant; $a$ represents the isotopic abundance of the detected element; $\sigma$ represents the reaction cross section of the element and neutron; $\lambda$ represents the branching ratio of $\gamma$ rays; $\varepsilon$ represents the detection efficiency of the all-energy peak.

\subsection{Development Direction of PGNAA Technology}

Since the first use of PGNAA technology to detect elements in 1936, the application research of PGNAA technology has started abroad [10] [11] [12]. In recent years, with the development of nuclear electronics instruments, the detector's ability to detect $\gamma$ rays has been continuously improved [13], and the rapid development of technologies such as neutron beam devices [14] [15] [16], nuclear databases [6] [17], and energy spectrum analysis [18] [19]. The prompt gamma neutron activation analysis technology has been widely used in the analysis of 
multi-element composition of large samples in many disciplines including environmental science [20] [21] [22], industry [23] [24] and health sciences [25] [26]. At this time, with the development of radioisotope neutron sources [27] and portable neutron generators [28], the technology has been able to conduct in-situ and rapid online analysis of large samples such as mining [29] [30], biological [31], manufacturing and construction quality control tasks [32] [33] [34], as well as homeland security contraband detection [35].

In recent years, with the widespread application and in-depth development of PGNAA technology, the international research hotspots mainly include the following three aspects:

1) PGNAA system methodology [36]: In the field of methodology, the research of prompt $\gamma$ neutron activation mainly includes the study of $\mathrm{k} 0$ method in the quantitative analysis of PGNAA technology [37] [38], the methodological study of the calibration of the wide energy range $\gamma$-ray detection efficiency [39], as well as evaluation and analysis techniques of $\gamma$ energy spectrum [19] [20] [40], etc.

2) PGNAA system device design: Since the late 20th century, with the progress and development of electronic technology and detection systems, the current development trend of PGNAA technology has also changed from increasing the neutron fluence rate to increasing the lower detection limit of elements, etc. On the other hand, compared with hot neutron beams [41] [42], the cold neutrons have a higher reaction cross-sections and lower energy; at the same time, due to the small fraction of fast neutrons in the cold neutron beam and the low $\gamma$-ray interference [43], the design and research of the cold neutron beam system with high fluence rate has become a hot spot in the world [43]-[48]. For example, in the US National Institute of Standards and Technology [49] [50] [51], Japan Atomic Energy Research Institute [52], Korea HANARO [53] [54] and other reactors have established their own advanced PGNAA system devices. In China, there are currently two PGNAA facilities in operation. One is prompt gamma neutron activation analysis (PGNAA) system based on the In-Hospital Neutron Irradiator (IHNI) developed for the Boron neutron capture therapy (BNCT) project on a $30 \mathrm{~kW}$ micro research reactor in Beijing [55]; the other is based on the Prompt gamma Neutron Activation Analysis (PGNAA) system on the China Advanced Research Reactor (CARR) [56] [57]. In recent years, in order to be able to irradiate the target sample with a higher neutron fluence rate to improve the sensitivity of PGNAA system analysis, a focused neutron beam analysis method has been proposed internationally [58] [59]. At the same time, the detection technology of Compton suppression gamma spectrometer was developed to improve the detection defects of low-energy gamma rays, which greatly reduced the Compton effect and improved the detection efficiency of low-energy gamma rays [60] [61].

3) Application of PGNAA technology: As a high-sensitivity, multi-element non-destructive online analysis method, PGNAA has been widely used in more 
than 30 PGNAA facilities worldwide. In recent years, PGNAA technology has proved to be valuable in a variety of applications, and its research field covers many aspects such as materials science, biology and medicine, earth science and cultural research.

\section{Application of PGNAA Technology in Industrial Material Inspection}

The use of the prompt gamma neutron activation analysis (PGNAA) method for the on-line analysis of the total element composition of industrial materials has been a hot spot in the field of nuclear detection and analysis in recent years [62]. Its application is mainly aimed at resource-intensive and high energy consumption industries such as coal, cement and metallurgy. This technology is used to conduct real-time detection of material composition in the production process so as to timely adjust the ratio of materials, so as to realize the optimization of the production process and ultimately improve the production efficiency [63]. For example, the coal blending process of thermal power, and the raw material proportioning process of cement and metallurgical industries can all use online testing equipment to reduce fuel consumption, improve production efficiency, and control product quality.

\subsection{Online Analysis and Detection of Coal}

Online detection of coal has been studied in the United States since the late 1970s. [1]. At the same time, its research and development equipment was applied to the Homer City Coal Preparation Plant in the United States in the 1980s to detect the low sulfur and low ash products of the coal preparation plant. Then developed Nucoalyzer, a coal detection device for power plants, which is based on 252 Cf neutron source and a set of high count rate spectrum processing system for online detection and analysis of coal [64]. Because the average energy of the neutrons emitted by the 252 Cf neutron source is low, it mainly reacts with the elements in the material to capture the thermal neutron, and the detection of key elements such as $\mathrm{C}$ and $\mathrm{O}$ in coal cannot be achieved [65]. Therefore, in 1995, Wombel et al. proposed a method for online analysis and research of coal using pulsed fast-thermal neutrons [66]. Subsequently, L. Dep et al. made further research on this basis, using pulsed neutron generator and BGO detector to realize the online analysis of major and minor elements in coal. The results showed that the accuracy of carbon in the sample can be nearly $1 \%$, and the accuracy of sulfur reached 0.05\% [67]. In 2001, Australia's M. Borsaru et al. applied PGNAA technology to coal borehole logging and measured the density of fly ash, iron, silicon, aluminum and coal seam downhole [68]. Later, the $252 \mathrm{Cf}$ neutron source and BGO detector were used to study the sulfur content in the coal seam [69]. From the 1990s, Thermo Electron Corporation of the United States carried out research and development of Coal analyser. Combined with PGNAA and PFTNA (Pulse Fast-Thermal Neutron Analysis) technology, it de- 
veloped the second-generation Coal Quality Manager FLEX, which can conduct accurate qualitative and quantitative analysis of $\mathrm{S}, \mathrm{Si}, \mathrm{Al}, \mathrm{Fe}, \mathrm{Na}$ and other elements and water content in Coal.

\subsection{Total Element Analysis of Cement Materials}

In the cement industry, Argentine scholar Daniel L. and others pioneered the analysis of elements in cement samples, and the analysis results showed that PGNAA technology could achieve the measurement of elements such as $\mathrm{Fe}, \mathrm{Ca}$, $\mathrm{Si}$ and $\mathrm{Cl}$ in the samples [70]. In 1999, R. Kheli et al. used Am-Be neutron source and high-purity germanium detector to measure the ratio of silicon to calcium in cement samples [71]. Saleh H. et al. have developed a device for detecting the content of chlorine in reinforced concrete [30]. In 2001, C.S. Lim et al. have developed the PGNAA cement on-line testing equipment on the conveyor belt. The equipment utilizes the inelastic scattering and capture reaction of the neutrons emitted by the Am-Be neutron source and the elements in the sample to realize the analysis of cement raw material elements, and the dual source detector is adopted to reduce the measurement error caused by uneven spatial distribution of the raw material components on the belt [72]. From 2009 to 2014, A.A. Naqvi et al. successively studied the cement dust and the elemental chlorine in cement, and analyzed the cement dust and concrete by the PGNAA technology to obtain the detection limit of elemental chlorine [73] [74] [75].

\subsection{Applications in the Mineral and Metallurgical Industries}

The iron and steel industry is an important pillar industry for national construction and national economic development, and is a basic industry for industrialization, as well as an intensive consumption of technology, capital, resources, and energy. The traditional detection techniques are mostly $\mathrm{X}$-ray fluorescence analysis, neutron activation analysis (NAA), etc., and with the help of the high-sensitivity analysis performance of PGNAA technology, research teams in various countries have begun to use PGNAA technology to carry out elements in various ores. Qualitative and quantitative analysis, as well as quality inspection in the production process of iron and steel smelting. During the metal smelting process, the presence of hydrogen may cause the brittleness of the material to increase, which has a great impact on the performance of the steel, so it has always been the focus of attention [76]. The Cold neutron instantaneous gamma activation analyzer at the National Institute of Standards and Technology (NIST) Center for Neutron Research (NCNR) has been shown to detect trace hydrogen in advanced materials such as titanium alloys [77]. In 2010, H.J. Cho et al. used PGNAA technology to analyze the hydrogen element in low-alloy steel and obtained good test results [78]. In 2017, the Danyal team used PGNAA technology to evaluate the performance of trace hydrogen elements in titanium alloys, and the uncertainty range was consistent with the experimental values [79]. In the application of ore element analysis, in 2009, Nicola's team used the PGNAA method to detect and analyze the $\mathrm{Cl}$ element in the ore sample. The re- 
sults showed that the uncertainty of the $\mathrm{Cl}$ element content was less than $5 \%$, which was the element of the ore. The analysis provides new technical methods [80].

\subsection{Domestic Research on PGNAA Material Detection Technology}

The on-line detection and analysis of the material composition of PGNAA technology first started in Europe and America and other developed countries. In recent years, with the vigorous development of nuclear technology applications, the domestic market has slowly started. In 1996, Chen Boxian et al. conducted a preliminary analysis of coal using the Am-Be neutron source, which provided a feasibility study for PGNAA technology to analyze the main elements in coal [81]. Subsequently, Song Zhaolong, Jia Wenbao and other teams have successively carried out the research of PGNAA technology in the field of online coal detection, and achieved remarkable results [82] [83]. In terms of elemental analysis of cement, Cao Xuepeng's team used D-D neutron generator as the neutron excitation source to carry out relevant research on the main elements of cement raw materials. The relative deviation of the measurement results is less than 7\%, which can meet the requirements of industrial production [84]. For the application of ore detection, Song qingfeng's team used PGNAA online analysis technology to measure the copper and nickel elements in the ore, and the detection accuracy can meet the requirements of online analysis of iron ore in the industrial site [85]. Then, through the combination of simulation and experiment, the team tested and verified the composition of iron ore pulp, and the results showed that the fitting degree of the experimental determination and analytical value of each component exceeded 0.99, proving the feasibility of PGNAA technology in the analysis of pulp composition [86].

\section{Development and Application of Industrial Online Detection System Based on PGNAA Technology}

The real-time online detection system of industrial material composition is mainly based on the PGNAA technology of isotope neutron source or neutron generator. By detecting the prompt $\gamma$-rays generated by the nuclear reaction between neutrons and nuclide in the material sample, and by online data analysis to obtain the element composition and content of the test object. A complete PGNAA online analysis system mainly includes three parts: field test, signal processing, data transmission and feedback. Among them, the on-site testing mainly includes detectors, neutron sources (or neutron generators), measuring mechanisms and protective devices; the signal processing part includes the spectrometer system, spectrometer analysis and data processing system; the data transmission and feedback part mainly includes the results display and data exchange of analyzer, industrial control unit, etc. [3].

\subsection{Overview of Foreign Industrial Online Detection Systems}

The traditional PGNAA industrial material online analysis system is mainly de- 
veloped based on isotope neutron source. In recent years, with the advancement of micro neutron generators and its unique advantages, it has gradually replaced the isotope neutron source and is used in the PGNAA industrial material online analysis system [1]. In the late 1980s, the original gamma metrics company (now Thermo Fisher Scientific) of the United States developed the first elemental composition analyzer for industrial sites after decades of technical research, and successfully applied it to the coal and cement industry [87]. At present, there are three major companies in the world that manufacture PGNAA systems for online real-time analysis of industrial material components: Thermo in the United States, Scantech in Australia, and Sodem in France [88]. The CB-Omni, which was launched by Thermo of the United States in 2006, is based on the isotope $252 \mathrm{Cf}$ neutron source. The detection system uses two NaI detectors, and its application field is mainly oriented to the mining and cement industry [87]. Scantech in Australia has mainly developed the COALSCAN 9500 analyzer for the coal industry and the GEOSCANTM analyzer for the cement industry. Both analyzers use $252 \mathrm{Cf}$ as the neutron source, among which, COALSCAN 9500 uses $\mathrm{NaI}$ detector as the detection system, which can perform complete online analysis of coal [89]; and GEOSCANTM uses multiple BGO detectors as the gamma rays of the device, and the detection system has a high $\gamma$ photon counting rate. The CAN device of Sodern in France uses an electrically controllable $\mathrm{D}-\mathrm{T}$ neutron generator as the neutron excitation source. Since the D-T neutron generator can provide neutrons with higher energy, it can generate inelastic scattering reaction with $\mathrm{C}, \mathrm{O}$ and other elements captured in the material with smaller cross sections to stimulate the prompt $\gamma$ rays. Therefore, the device can realize full-element analysis, and its analysis index is more comprehensive. At the same time, based on the advantage of neutron source electrical controllability, it can provide a safer environment for equipment maintenance [90].

\subsection{Research and Application of Domestic Industrial Material Detection System}

Now in Europe and America and other developed countries, the development and manufacturing of PGNAA technology-based real-time online detection system for industrial material composition has already formed a relatively mature industrial chain, and is sold through relevant enterprises. With the development of our country's industrial technology, domestic demand for real-time online detection systems for industrial materials has gradually increased. In the early 1990s, aluminum plants such as Shandong and Zhengzhou began to use the NH-501 system based on PGNAA technology for industrial online test and measurement [3]. Since the beginning of this century, the domestic market has become active. Based on the use of foreign equipment, Nanjing Continental Technology has achieved localization through innovation and reconstruction. Afterwards, scientific research units such as Kelun Company of Northeast Normal University, China Academy of Engineering Physics, Tsinghua University and China Atomic Energy Research Institute also launched related PGNAA 
projects [24]. Based on the modern nuclear analysis technology, a series of testing equipment for the analysis of industrial components such as coal and cement has been developed and produced. Its quality and technology have made greater progress than before, but compared with similar products abroad, there is still a big gap in performance. High-sensitivity, multi-parameter measurement of high-end industrial material composition real-time online in-situ detection system still needs to rely on foreign imports.

Based on the good application prospects of PGNAA technology in China's industrial material detection technology, the National Ministry of Science and Technology established a special project for the development of national major scientific instruments and equipment in 2013: "Real-time online detection of industrial material components based on prompt gamma-ray neutron activation analysis technology System". The project is led by Nanjing University of Aeronautics and Astronautics, where Academician Chen Da's team is located, and cooperates with 8 units including Lanzhou University and Northeast Normal University. It aims at energy conservation and consumption reduction in China's resource-intensive and consumable industries, from national industrial development and material composition. Starting from the new trend of analysis technology, developed a real-time online detection instrument for industrial material components with national independent intellectual property rights and reaching the international advanced level. The instrument is based on the prompt $\gamma$ neutron activation analysis technology, uses the neutrons generated by the controllable small D-D/mini D-T neutron source, after being modulated by the slowing multiplication system, bombards the measured material to produce prompt characteristic $\gamma$ rays, using the new high-efficiency $\gamma$-ray detection system obtains the $\gamma$ energy spectrum and analyzes it to obtain the main elements and their contents in the material [91]. In this project, the two key technologies at the core are: the development of high-yield, long-life D-D small neutron sources, miniaturized of a long-life D-T sealed neutron sources, and the development of high-count rate detection systems [92]. At present, the project has completed the application development research in the fields of thermal power plants, ironworks, cement plants, etc., has built three demonstration projects, and passed the self-acceptance phase in December 2018.

\section{Summary}

As an effective nuclear analysis technique, prompt gamma neutron activation analysis plays an important role in the on-line analysis of industrial materials, especially in the detection of irregular bulk materials. Nowadays, PGNAA technology is relatively mature in terms of principles and basic applications. In recent years, international scientific research teams have carried out further research in the development of new detectors such as high resolution, development of energy spectrum analysis and application development of portable neutron sources. On the other hand, the neutrons and gamma rays arising from the 
neutron source are severely harmful to the human body. Processing and optimizing the various parameters of the PGNAA system setup under the irradiation of a neutron source is dangerous and time consuming. The Monte Carlo method has a huge advantage in complex particle transportation. Therefore, many scholars have studied the Monte Carlo method, which has become a hot spot in the world.

In summary, after more than half a century of development, the application of the instantaneous gamma neutron activation analysis technology in the detection of industrial materials has reached a relatively high level in developed countries such as Europe and America. With the strong support of the country and the unremitting efforts of the scientific research team, the technical level of PGNAA in China has made remarkable progress, but there are still gaps. It is necessary to continuously realize the improvement of technology, strengthen the in-depth integration of production, education and research, and localize the PGNAA technology. And maturely applied to the online detection of industrial materials.

\section{Conflicts of Interest}

The authors declare no conflicts of interest regarding the publication of this paper.

\section{References}

[1] Hei, D.Q. (2014) Development and Status of PGNAA Online Analysis Technology. Science \& Technology Information, 12, 63-64. (In Chinese)

[2] Jia, W.B., Cheng, C., Shan, Q., et al. (2015) Study on the Elements Detection and Its Correction in Aqueous Solution. Nuclear Instruments and Methods in Physics Research Section B: Beam Interactions with Materials and Atoms, 342, 240-243. https://doi.org/10.1016/j.nimb.2014.10.010

[3] He, L.L., Yang, J.B., Mu, K.L., et al. (2005) Development and Applications of the On-Line Analysis System Based on PGNAA Technology. Computing Techniques for Geophysical and Geochemical Exploration, 27, 317-320. (In Chinese)

[4] Oliveira, C., Salgado, J. and Carvalho, F. (1997) Optimation of PGNAA Instrument Design for Cement Raw Materials Using the MCNP Code. Journal of Radioanalytical and Nuclear Chemistry, 216, 191-198. https://doi.org/10.1007/BF02033777

[5] Yang, J.B., Yang, Y.G., Li, Y.J., et al. (2013) Prompt Gamma Neutron Activation Analysis for Multi-Element Measurement with Series Samples. Laser Physics Letters, 10, Article ID: 056002. https://doi.org/10.1088/1612-2011/10/5/056002

[6] Molnar, G. (2004) Handbook of Prompt Gamma Activation Analysis: With Neutron Beams. Springer Science \& Business Media, Berlin.

[7] Zhang, L.Z., Ni, B.F., Tian, W.Z., et al. (2005) Status and Development of Prompt $\gamma$-Ray Neutron Activation Analysis. Atomic Energy Science and Technology, 39, 282-288. (In Chinese)

[8] Paul, R.L. and Lindstrom, R.M. (2000) Prompt Gamma-Ray Activation Analysis: Fundamentals and Applications. Journal of Radioanalytical and Nuclear Chemistry, 243, 181-189. https://doi.org/10.1023/A:1006796003933 
[9] Sudarshan, K., Acharya, R.N., Nair, A.G.C., et al. (2001) Determination of Prompt K0 Factors in PGNAA.

[10] Duffey, D., El-Kady, A. and Senftle, F.E. (1970) Analytical Sensitivities and Energies of Thermal-Neutron-Capture Gamma Rays. Nuclear Instruments and Methods, 80, 149-171. https://doi.org/10.1016/0029-554X(70)90311-3

[11] Liu, Y.R., Lu, Y.X., Xie, Y.L., et al. (1991) Development and Applications of an On-Line Thermal Neutron Prompt-Gamma Element Analysis System. Journal of Radioanalytical and Nuclear Chemistry, 151, 83-93. https://doi.org/10.1007/BF02040133

[12] Liu, Y.R. and Jing, S.W. (2003) The Progress of Neutron Induced Prompt Gamma Analysis Technique in 1988-2002. Journal of Isotopes, 16, 106-110. (In Chinese)

[13] Naqvi, A.A., Al-Anezi, M.S., Kalakada, Z., et al. (2012) Response Tests of a LaCl3: Ce Scintillation Detector with Low Energy Prompt Gamma Rays from Boron and Cadmium. Applied Radiation and Isotopes, 70, 882-887. https://doi.org/10.1016/j.apradiso.2012.01.023

[14] Belgya, T., Molnár, G.L., Révay, Z., et al. (2005) Determination of Thermal Neutron Capture Cross Sections Using Cold Neutron Beams. AIP Conference Proceedings. American Institute of Physics, 769, 744-747. https://doi.org/10.1063/1.1945114

[15] Révay, Z., Belgya, T. and Firestone, R.B. (2007) Determination of Thermal Neutron Capture Cross-Sections at Budapest PGAA Facility. AIP Conference Proceedings. American Institute of Physics, 947, 445-448. https://doi.org/10.1063/1.2813850

[16] Žerovnik, G., Becker, B., Belgya, T., et al. (2015) Systematic Effects on Cross-Section Data Derived from Reaction Rates at a Cold Neutron Beam. Nuclear Instruments and Methods in Physics Research Section A: Accelerators, Spectrometers, Detectors and Associated Equipment, 799, 29-36. https://doi.org/10.1016/j.nima.2015.07.008

[17] Choi, H.D., Firestone, R.B., Lindstrom, R.M., Molnar, G.L., Mugh-abghab, S.F., Paviotti-Corcuera, R, Revay, Z., Trkov, A., Zerkin, V. and Zhou, C. (2007) Database of Prompt Gamma Rays from Slow Neutron Capture for Elemental Analysis (STI/PUB/ 1263). IAEA, Vienna.

[18] Révay, Z., Belgya, T. and Molnár, G.L. (2005) Application of Hypermet-PC in PGAA. Journal of Radioanalytical and Nuclear Chemistry, 265, 261-265. https://doi.org/10.1007/s10967-005-0818-2

[19] Osawa, T. (2015) Development of an Automatic Prompt Gamma-Ray Activation Analysis System. Journal of Radioanalytical and Nuclear Chemistry, 303, 1141-1146. https://doi.org/10.1007/s10967-014-3436-Z

[20] Zhang, Y., Jia, W.B., Gardner, R., et al. (2018) Study on the PGNAA Measurement of Heavy Metals in Aqueous Solution by the Monte Carlo-Library Least-Squares (MCLLS) Approach. Applied Radiation and Isotopes, 132, 13-17. https://doi.org/10.1016/j.apradiso.2017.10.037

[21] Howell, S.L., Sigg, R.A., Moore, F.S., et al. (2000) Calibration and Validation of a Monte Carlo Model for PGNAA of Chlorine in Soil. Journal of Radioanalytical and Nuclear Chemistry, 244, 173-178. https://doi.org/10.1023/A:1006740921047

[22] Idiri, Z., Mazrou, H., Amokrane, A., et al. (2010) Characterization of an Am-Be PGNAA Set-Up Developed for in Situ Liquid Analysis: Application to Domestic Waste Water and Industrial Liquid Effluents Analysis. Nuclear Instruments and Methods in Physics Research Section B: Beam Interactions with Materials and Atoms, 268, 213-218. https://doi.org/10.1016/j.nimb.2009.10.185

[23] Wilde, H. and Herzog, W. (1982) On-Line Analysis of Coal by Neutron Induced Gamma Spectrometry. Journal of Radioanalytical Chemistry, 71, 253-264. 
https://doi.org/10.1007/BF02516154

[24] Jia, W.B., Hei, D.Q. and Shan, Q. (2011) Application Status and Problems of PGNAA Technology in Domestic Coal Industry. Proceedings of the 2011 Annual Meeting of the Chinese Nuclear Society, Guiyang, 156-161. (In Chinese)

[25] Grinyer, J., Byun, S.H. and Chettle, D.R. (2005) In Vivo Prompt Gamma Neutron Activation Analysis of Cadmium in the Kidney and Liver. Applied Radiation and Isotopes, 63, 475-479. https://doi.org/10.1016/j.apradiso.2005.05.046

[26] Yang, J., Peng, K., Qiao, Y., et al. (2018) Monte Carlo Simulation of Biological Shielding Parameters in PGNAA. Micro \& Nano Letters, 13, 457-460. https://doi.org/10.1049/mnl.2017.0644

[27] Fantidis, J.G., Nicolaou, G.E., Potolias, C., et al. (2011) The Comparison of Four Neutron Sources for Prompt Gamma Neutron Activation Analysis (PGNAA) in Vivo Detections of Boron. Journal of Radioanalytical and Nuclear Chemistry, 290, 289. https://doi.org/10.1007/s10967-011-1315-4

[28] Marchese, N., Cannuli, A., Caccamo, M.T., et al. (2017) New Generation Non-Stationary Portable Neutron Generators for Biophysical Applications of Neutron Activation Analysis. Biochimica et Biophysica Acta (BBA)-General Subjects, 1861, 3661-3670. https://doi.org/10.1016/j.bbagen.2016.05.023

[29] Zhang, F. and Liu, J.-T. (2014) Monte Carlo Simulation of PGNAA System for Determining Element Content in the Rock Sample. Journal of Radioanalytical and Nuclear Chemistry, 299, 1219-1224. https://doi.org/10.1007/s10967-013-2858-3

[30] Naqvi, A.A., Al-Anezi, M.S., Kalakada, Z., et al. (2011) Detection Efficiency of Low Levels of Boron and Cadmium with a LaBr3: Ce Scintillation Detector. Nuclear Instruments and Methods in Physics Research Section A: Accelerators, Spectrometers, Detectors and Associated Equipment, 665, 74-79. https://doi.org/10.1016/j.nima.2011.10.010

[31] Ghorbani, P., Sardari, D., Bayat, E., et al. (2012) Neutron Beam Preparation with Am-Be Source for Analysis of Biological Samples with PGNAA Method. Journal of Radioanalytical and Nuclear Chemistry, 291, 839-842. https://doi.org/10.1007/s10967-011-1359-5

[32] Livingston, R.A., Al-Sheikhly, M. and Mohamed, A.B. (2010) Numerical Simulation of the PGNA Signal from Chlorine Diffusion Gradients in Concrete. Applied Radiation and Isotopes, 68, 679-682. https://doi.org/10.1016/j.apradiso.2010.01.029

[33] Naqvi, A.A., Al-Matouq, F.A., Khiari, F.Z., et al. (2013) Optimization of a Prompt Gamma Setup for Analysis of Environmental Samples. Journal of Radioanalytical and Nuclear Chemistry, 296, 215-221. https://doi.org/10.1007/s10967-012-2045-y

[34] Saleh, H. and Livingston, R. (2000) Experimental Evaluation of a Portable Neutron-Based Gamma-Spectroscopy System for Chloride Measurements in Reinforced Concrete. Journal of Radioanalytical and Nuclear Chemistry, 244, 367-371. https://doi.org/10.1023/A:1006787626016

[35] Vourvopoulos, G. and Womble, P.C. (2001) Pulsed Fast/Thermal Neutron Analysis: A Technique for Explosives Detection. Talanta, 54, 459-468. https://doi.org/10.1016/S0039-9140(00)00544-0

[36] Wang, X.H., Shun, H.C., Yao, Y.G., et al. (2014) Development and Status of Prompt Gamma Neutron Activation Analysis Technique Methodology. Journal of Isotopes, No. 4, 251-256. (In Chinese)

[37] Révay, Z. and Kennedy, G. (2012) Application of the K0 Method in Neutron Activation Analysis and in Prompt Gamma Activation Analysis. Radiochimica Acta, 100, 687-698. https://doi.org/10.1524/ract.2012.1957 
[38] Li, D.H. (2006) K Method of Instantaneous Gamma Neutron Activation Analysis and Its Application. Lanzhou University, Lanzhou. (In Chinese)

[39] Molnár, G.L., Révay, Z. and Belgya, T. (2002) Wide Energy Range Efficiency Calibration Method for Ge Detectors. Nuclear Instruments and Methods in Physics Research Section A: Accelerators, Spectrometers, Detectors and Associated Equipment, 489, 140-159. https://doi.org/10.1016/S0168-9002(02)00902-6

[40] Révay, Z. (2009) Determining Elemental Composition Using Prompt $\gamma$ Activation Analysis. Analytical Chemistry, 81, 6851-6859. https://doi.org/10.1021/ac9011705

[41] Gladney, E.S., Curtis, D.B. and Jurney, E.T. (1978) Multielement Analysis of Major and Minor Elements by Thermal Neutron Induced Capture Gamma-Ray Spectrometry. Journal of RadioAnalytical Chemistry, 46, 299-308. https://doi.org/10.1007/BF02519896

[42] Molnár, G., Belgya, T., Dabolczi, L., et al. (1997) The New Prompt Gamma-Activation Analysis Facility at Budapest. Journal of Radioanalytical and Nuclear Chemistry, 215, 111-115. https://doi.org/10.1007/BF02109886

[43] Lindstrom, R.M., Zeisler, R. and Rossbach, M. (1987) Activation Analysis Opportunities Using Cold Neutron Beams. Journal of Radioanalytical and Nuclear Chemistry, 112, 321-330. https://doi.org/10.1007/BF02132364

[44] Lindstrom, R.M., Zeisler, R., Vincent, D.H., et al. (1993) Neutron Captue Prompt Gamma-Ray Activation Analysis at the NIST Cold Neutron Research Facility. Journal of Radioanalytical and Nuclear Chemistry, 167, 121-126. https://doi.org/10.1007/BF02035470

[45] Molnár, G., Révay, Z.S., Veres, Á., et al. (1993) Cold Neutron Facility for Prompt Gamma-Neutron Activation Analysis. Journal of Radioanalytical and Nuclear Chemistry, 167, 133-137. https://doi.org/10.1007/BF02035472

[46] Ünlü, K., Rios-Martinez, C. and Wehring, B.W. (1995) Prompt Gamma Activation Analysis with the Texas Cold Neutron Source. Journal of Radioanalytical and Nuclear Chemistry, 193, 145-154. https://doi.org/10.1007/BF02041928

[47] Révay, Z., Belgya, T., Kasztovszky, Z., et al. (2004) Cold Neutron PGAA Facility at Budapest. Nuclear Instruments and Methods in Physics Research Section B: Beam Interactions with Materials and Atoms, 213, 385-388. https://doi.org/10.1016/S0168-583X(03)01653-7

[48] Couet, A., Motta, A.T., Comstock, R.J., et al. (2012) Cold Neutron Prompt Gamma Activation Analysis, a Non-Destructive Technique for Hydrogen Level Assessment in Zirconium Alloys. Journal of Nuclear Materials, 425, 211-217. https://doi.org/10.1016/j.jnucmat.2011.06.044

[49] Mackey, E.A., Anderson, D.L., Liposky, P.J., et al. (2004) New Thermal Neutron Prompt $\gamma$-Ray Activation Analysis Instrument at the National Institute of Standards and Technology Center for Neutron Research. Nuclear Instruments and Methods in Physics Research Section B: Beam Interactions with Materials and Atoms, 226, 426-440. https://doi.org/10.1016/j.nimb.2004.05.038

[50] Paul, R.L., Şahin, D., Cook, J.C., et al. (2015) NGD Cold-Neutron Prompt Gamma-Ray Activation Analysis Spectrometer at NIST. Journal of Radioanalytical and Nuclear Chemistry, 304, 189-193. https://doi.org/10.1007/s10967-014-3635-7

[51] Turkoglu, D., Downing, R.G., Chen, W., et al. (2017) A 3 He Beam Stop for Minimizing Gamma-Ray and Fast-Neutron Background. Journal of Radioanalytical and Nuclear Chemistry, 311, 1243-1249. https://doi.org/10.1007/s10967-016-4954-7

[52] Toh, Y., Oshima, M., Furutaka, K., et al. (2008) Development of a Neutron Beam Line and Detector System for Multiple Prompt Gamma-Ray Analysis. Journal of 
Radioanalytical and Nuclear Chemistry, 278, 703-706.

https://doi.org/10.1007/s10967-008-1508-7

[53] Park, C.S., Sun, G.M., Byun, S.H., et al. (2005) Progress of Prompt Gamma Activation Analysis in Korea. Journal of Radioanalytical and Nuclear Chemistry, 265, 283-286. https://doi.org/10.1007/s10967-005-0821-7

[54] Choi, H.D., Byun, S.H., Sun, G.M., et al. (2001) Development of PGNAA Facility in HANARO.

[55] Zhang, Z., Chong, Y., Chen, X., et al. (2015) PGNAA System Preliminary Design and Measurement of In-Hospital Neutron Irradiator for Boron Concentration Measurement. Applied Radiation and Isotopes, 106, 161-165. https://doi.org/10.1016/j.apradiso.2015.07.049

[56] Ni, B., Xiao, C., Huang, D., et al. (2012) A Brief Introduction to NAA Facilities of China Advance Research Reactor at CIAE. Journal of Radioanalytical and Nuclear Chemistry, 291, 313-319. https://doi.org/10.1007/s10967-011-1252-2

[57] Sun, H.C., Ni, B.F., et al. (2013) Design of a Prompt-Gamma Neutron Activation Analysis System on China Advanced Research Reactor. Nuclear Technology (English Version), 22, 287-292.

[58] Chen-Mayer, H.H., Lamaze, G.P., Mildner, D.F.R., et al. (2002) Neutron Imaging and Prompt Gamma Activation Analysis Using a Monolithic Capillary Neutron Lens. In: Analytical Sciences/Supplements Proceedings of IUPAC International Congress on Analytical Sciences 2001 (ICAS 2001), The Japan Society for Analytical Chemistry, Tokyo, i629-i632.

[59] Chen-Mayer, H.H., Heward, W.J., Paul, R.L., et al. (2003) Distribution of Chlorine in Quartz Determined by Neutron Beam Focusing Prompt Gamma Activation Analysis and Micro-X-Ray Fluorescence. Journal of Materials Research, 18, 2486-2493. https://doi.org/10.1557/JMR.2003.0346

[60] Cho, H.J., Chung, Y.S. and Kim, Y.J. (2005) Study on Prompt Gamma-Ray Spectrometer Using Compton Suppression System. Nuclear Instruments and Methods in Physics Research Section B: Beam Interactions with Materials and Atoms, 229, 499-507. https://doi.org/10.1016/j.nimb.2004.12.124

[61] Szentmiklósi, L., Kis, Z., Belgya, T., et al. (2013) On the Design and Installation of a Compton-Suppressed HPGe Spectrometer at the Budapest Neutron-Induced Prompt Gamma Spectroscopy (NIPS) Facility. Journal of Radioanalytical and Nuclear Chemistry, 298, 1605-1611. https://doi.org/10.1007/s10967-013-2555-2

[62] Li, T.Z., Chen, B.X., Shi, H.X., et al. (2004) Monte Carlo Simulation in PGNAA. Nuclear Electronics \& Detection Technology, 24, 136-139, 146. (In Chinese)

[63] Wu, Z.Q. and Gong, Y.L. (2018) Nonlinear Study of Elemental Measurements by PGNAA Method. Journal of Isotopes, 31, 343-350. (In Chinese)

[64] McQuaid, J.H., Brown, D.R., Gozani, T., et al. (1981) High Rate Spectroscopy for On-Line Nuclear Coal Analyzer (Nucoalyzer TM Conac). IEEE Transactions on Nuclear Science, 28, 304-307. https://doi.org/10.1109/TNS.1981.4331185

[65] Chen, X.W. (2006) Study on the Method of On-Line Measuring Coal Components by PGNAA. Lanzhou University, Lanzhou. (In Chinese)

[66] Womble, P.C., Schultz, F.J. and Vourvopoulos, G. (1995) Non-Destructive Characterization Using Pulsed Fast-Thermal Neutrons. Nuclear Instruments and Methods in Physics Research Section B: Beam Interactions with Materials and Atoms, 99, 757-760. https://doi.org/10.1016/0168-583X(95)00326-6

[67] Dep, L., Belbot, M., Vourvopoulos, G., et al. (1998) Pulsed Neutron-Based On-Line 
Coal Analysis. Journal of Radioanalytical and Nuclear Chemistry, 234, 107-112. https://doi.org/10.1007/BF02389756

[68] Borsaru, M., Biggs, M., Nichols, W., et al. (2001) The Application of PromptGamma Neutron Activation Analysis to Borehole Logging for Coal. Applied Radiation and Isotopes, 54, 335-343. https://doi.org/10.1016/S0969-8043(00)00109-3

[69] Borsaru, M., Berry, M., Biggs, M., et al. (2004) In Situ Determination of Sulphur in Coal Seams and Overburden Rock by PGNAA. Nuclear Instruments and Methods in Physics Research Section B: Beam Interactions with Materials and Atoms, 213, 530-534. https://doi.org/10.1016/S0168-583X(03)01623-9

[70] Savio, D.L.C., Mariscotti, M.A.J. and Guevara, S.R. (1995) Elemental Analysis of a Concrete Sample by Capture Gamma Rays with a Radioisotope Neutron Source. Nuclear Instruments and Methods in Physics Research Section B: Beam Interactions with Materials and Atoms, 95, 379-388. https://doi.org/10.1016/0168-583X(94)00424-2

[71] Khelifi, R., Idiri, Z., Omari, L., et al. (1999) Prompt Gamma Neutron Activation Analysis of Bulk Concrete Samples with an Am-Be Neutron Source. Applied Radiation and Isotopes, 51, 9-13. https://doi.org/10.1016/S0969-8043(98)00184-5

[72] Lim, C.S., Tickner, J., Sowerby, B.D., et al. (2001) An On-Belt Elemental Analyser for the Cement Industry. Applied Radiation and Isotopes, 54, 11-19. https://doi.org/10.1016/S0969-8043(00)00180-9

[73] Naqvi, A.A., Garwan, M.A., Nagadi, M.M., et al. (2009) Non-Destructive Analysis of Chlorine in Fly Ash Cement Concrete. Nuclear Instruments and Methods in Physics Research Section A: Accelerators, Spectrometers, Detectors and Associated Equipment, 607, 446-450. https://doi.org/10.1016/j.nima.2009.05.192

[74] Naqvi, A.A., Maslehuddin, M., Garwan, M.A., et al. (2011) Estimation of Minimum Detectable Concentration of Chlorine in the Blast Furnace Slag Cement Concrete. Nuclear Instruments and Methods in Physics Research Section B: Beam Interactions with Materials and Atoms, 269, 1-6. https://doi.org/10.1016/j.nimb.2010.10.006

[75] Naqvi, A.A., Maslehuddin, M., Kalakada, Z., et al. (2014) Prompt Gamma Ray Evaluation for Chlorine Analysis in Blended Cement Concrete. Applied Radiation and Isotopes, 94, 8-13. https://doi.org/10.1016/j.apradiso.2014.06.011

[76] Paul, R.L. and Lindstrom, R.M. (2012) Preparation and Certification of Hydrogen in Titanium Alloy Standard Reference Materials. Metallurgical and Materials Transactions A, 43, 4888-4895. https://doi.org/10.1007/s11661-012-1306-2

[77] Paul, R.L. (2006) Measurement of Hydrogen in Advanced Materials by Cold Neutron Prompt Gamma-Ray Activation Analysis. AIP Conference Proceedings. American Institute of Physics, 837, 223-229. https://doi.org/10.1063/1.2213077

[78] Cho, H.J. and Park, K.W. (2010) Analysis of Hydrogen Concentration in Low-Alloy Steel. Journal of Radioanalytical and Nuclear Chemistry, 284, 533-537. https://doi.org/10.1007/s10967-010-0506-8

[79] Turkoglu, D., Chen-Mayer, H., Paul, R., et al. (2017) Assessment of PGAA Capability for Low-Level Measurements of $\mathrm{H}$ in Ti Alloys. Analyst, 142, 3822-3829. https://doi.org/10.1039/C7AN01308F

[80] Di Nicola, L., Schnabel, C., Wilcken, K.M., et al. (2009) Determination of Chlorine Concentrations in Whole Rock: Comparison between Prompt-Gamma Activation and Isotope-Dilution AMS Analysis. Quaternary Geochronology, 4, 501-507. https://doi.org/10.1016/j.quageo.2009.08.001

[81] Chen, B.X. and He, J.Y. (1996) Multi-Element Analysis of Neutron-Induced Instant $\gamma$-Ray Coal. Nuclear Electronics \& Detection Technology, 16, 6-12. (In Chinese) 
[82] Song, Z.L., Lv, Z.Z. and Lu, H.P. (2001) On-Line Element Analysis System of Coal Based on Prompt Gamma-Ray Analysis Method. Proceedings of the CSEE, 21, 89-92, 96. (In Chinese)

[83] Jia, W.B., Hei, D.Q., Xu, A.G., et al. (2011) Influence of Sample Weight in Coal Composition Online Analysis by PGNAA. Atomic Energy Science and Technology, 45, 1011-1014. (In Chinese)

[84] Cao, X.P., Chen, X.H., Zhang, H.Y., et al. (2011) Elemental Contents in Cement Raw Meal Using D-D Neutron Generator. Atomic Energy Science and Technology, 45, 108-111. (In Chinese)

[85] Song, Q.F., Zhang, W., Gong, Y.L., et al. (2014) Application Research on On-Line Detection of Copper-Nickel Ore Using Instant Gamma Neutron Activation Analysis Technology. World Nonferrous Metals, No. 2, 72-73. (In Chinese)

[86] Gong, Y.L., Zhao, L., Song, Q.F., et al. (2018) Experiment on Detection of Iron Pulp Composition by PGNAA Technology. Modern Mining, No. 8, 116-117, 122. (In Chinese)

[87] Leetham, D. and Fisher, T. (2008) Online Stockpile Analysis. World Cement, 39, 89-93.

[88] Liu, Y.Z. (2017) Research on High Count Rate Detector System Based on PGNAA Technology for Real-Time Online Detection System of Industrial Material Composition. University of Science and Technology of China, Hefei. (In Chinese)

[89] Borsaru, M. and Jecny, Z. (2001) Application of PGNAA for Bulk Coal Samples in a $4 \pi$ Geometry. Applied Radiation and Isotopes, 54, 519-526. https://doi.org/10.1016/S0969-8043(99)00276-6

[90] Cai, P.K. (2017) Development of Moderation and Reflection Multiplier in On-Line Analysis Instrument for Material Composition Based on PGNAA Technology. Nanjing University of Aeronautics and Astronautics, Nanjing. (In Chinese)

[91] Jia, W.B. (2014) Progress Report on the Development and Application of Real-Time Online Detection of Industrial Material Composition. Nanjing University of Aeronautics and Astronautics, Nanjing. (In Chinese)

[92] Wang, B.C. (2018) Research on Upgrading of Real-Time Online Detection System of Industrial Material Composition Based on PGNAA Technology. University of Science and Technology of China, Hefei. (In Chinese) 